\title{
¿Hacia un tratado internacional sobre la responsabilidad de las empresas en el ámbito de los derechos humanos? Reflexiones sobre la primera sesión del grupo de trabajo intergubernamental de composición abierta
}

\author{
Towards an International Treaty on Corporate \\ Responsibility in the Field of Human Rights? \\ Reflections on the First Session of the Open-Ended \\ Intergovernmental Working Group
}

\author{
Humberto CANTú RIVERA*
}

\begin{abstract}
SUMARIO: I. Introducción. II. La propuesta de Ecuador y Sudáfrica sobre un instrumento internacional vinculante, y el voto de continuidad a la difusión e implementación de los Principios Rectores de la ONU sobre las empresas y los derechos humanos. III. Posibilidades y desafíos de un tratado internacional sobre la responsabilidad empresarial en el ámbito de los derechos humanos. IV. Breves reflexiones sobre la primera sesión del Grupo de Trabajo Intergubernamental de composición abierta sobre el proyecto del tratado. V. Conclusiones. VI. Bibliografía.
\end{abstract}

* Investigador asociado del Centro de Investigación sobre Derechos Humanos y Derecho Humanitario (CRDH) de la Universidad Panthéon-Assas Paris II; miembro del Grupo de Estudio sobre empresas y derechos humanos de la International Law Association.

Artículo recibido el 4 de agosto de 2015 Aprobado para publicación el 31 de agosto de 2015 
Resumen: La adopción de los Principios Rectores de la ONU sobre las empresas y los derechos humanos en 2011 significó el inicio de un proceso de desarrollo normativo a gran escala a nivel internacional, regional y nacional. Este proceso dio un siguiente paso con el establecimiento por el Consejo de Derechos Humanos de Naciones Unidas de un Grupo de Trabajo intergubernamental de composición abierta, encargado de desarrollar un instrumento internacional jurídicamente vinculante en la materia. Dicho Grupo de Trabajo intergubernamental tuvo su primera sesión en julio de 2015, donde se ventilaron e intercambiaron ideas sobre algunos de los principales puntos a cubrir en el tratado, pero donde también resaltaron numerosos desafíos que deben ser analizados a fondo si se busca crear un instrumento efectivo.

Palabras clave: ONU, derechos humanos, empresas, Grupo de Trabajo intergubernamental, primera sesión.

ABSTRACT: The adoption of the UN Guiding Principles on Business and Human Rights in 2011 started a process of large-scale normative development at the international, regional and domestic level. This process moved forward with the establishment by the Human Rights Council of an Open-Ended Intergovernmental Working Group, whose task is the development of an international legally binding instrument in this field. The Intergovernmental Working Group had its first session in July 2015, where numerous ideas on several of the issues and key challenges that the prospective treaty will face were discussed. These issues and challenges need to be analyzed in depth if an effective international instrument is to be developed.

Key words: UN, human rights, business, Intergovernmental Working Group, first session.

RÉSUMÉ: L'adoption des Principes directeurs des Nations Unies relatifs aux entreprises et aux droits de l'homme en 2011 a marqué le début d'un processus de développement normatif à grande échelle, à niveau international, régional et national. L'établissement par le Conseil des droits de l'homme d'un Groupe de travail intergouvernemental à composition non limitée chargé d'élaborer un instrument international juridiquement contraignant dans la matière en constitue le deuxième pas. Ce Groupe de travail a eu sa première session en juillet 2015, où nombreuses idées sur plusieurs thèmes et défis auxquels le traité se confrontera ont été discutés. Il est donc nécessaire que ces questions soient analysées de façon approfondie pour assurer l'effectivité du futur instrument international.

Mots-clés: Nations Unies, droits de l'homme, entreprises, Groupe de travail intergouvernemental, première session. 


\section{INTRODUCCIÓN}

La responsabilidad del sector empresarial por su impacto en la protección de los derechos humanos y el medio ambiente es un tema que ha estado durante más de cuarenta años en la agenda internacional de forma intermitente. ${ }^{1}$ La adopción por consenso de los Principios Rectores sobre las empresas y los derechos humanos ${ }^{2}$ en el Consejo de Derechos Humanos de la ONU en 2011, como punto culminante del mandato de John Ruggie como representante especial del secretario general sobre los derechos humanos y las empresas transnacionales, sirvió para instalar de forma permanente el tema en la agenda del organismo internacional. Como su propio autor lo reconoció, se trató de la fase final del inicio de un proyecto que, partiendo de una base común en donde se reconocen obligaciones y responsabilidades diferenciadas, necesita continuar construyendo un andamiaje jurídico a nivel internacional para garantizar la protección y realización de los derechos humanos ante los impactos producidos por las empresas, independientemente de su tamaño o giro. ${ }^{3}$

Desde luego, los Principios Rectores fueron sujeto de numerosas críticas, ${ }^{4}$ en virtud de la aparente laxa convicción de establecer obligacio-

1 Para una referencia general más amplia sobre el tema, véanse Jägers, N., Corporate Human Rights Obligations: In Search of Accountability, Antwerp, Intersentia, 2002, pp. 119-130; Sauvant, K. P., 'The Negotiations of the United Nations Code of Conduct on Transnational Corporations: Experience and Lessons Learned', The Journal of World Investment \& Trade, vol. 16, 2015; Bair, J., 'Corporations at the United Nations: Echoes of the New International Economic Order?', Humanity: An International Journal of Human Rights, Humanitarianism, and Development, vol. 6(1), 2015; Cantú Rivera, H. F., 'Empresas y derechos humanos: ¿Hacia una regulación jurídica efectiva o el mantenimiento del status quo?', Anuario Mexicano de Derecho Internacional, vol. XIII, 2013, pp. 316-325.

2 Representante Especial del Secretario General sobre la cuestión de los derechos humanos y las empresas transnacionales y otras empresas comerciales, Principios Rectores sobre las empresas y los derechos humanos: puesta en práctica del marco de las Naciones Unidas para "proteger, respetar y remediar", A/HRC/17/31 (21 de marzo de 2011).

3 Ruggie, J. G., Just Business: Multinational Corporations and Human Rights, Nueva York, W.W. Norton \& Co., 2013, p. 124.

4 Sobre este punto, véanse particularmente Deva, S., "Treating Human Rights Lightly: a Critique of the Consensus Rhetoric and the Language Employed by the Guiding Princi- 
Esta revista forma parte del acervo de la Biblioteca Jurídica Virtual del Instituto de Investigaciones Jurídicas de la UNAM www.juridicas.unam. $\mathrm{mx}$

nes jurídicas para las empresas, de haber descartado proponer opciones en relación con la competencia extraterritorial de los Estados para perseguir y castigar violaciones a los derechos humanos por las empresas, o de no establecer un mecanismo para el monitoreo de su implementación. Por supuesto, algunas de esas críticas podrían haber sido merecidas, aunque ciertamente ignoran la dificultad de lograr acuerdos políticos en esa esfera para establecer una base común ${ }^{5} \mathrm{y}$, conforme al mandato del Consejo de Derechos Humanos tras la renovación del mandato en 2008, para hacer operativo el marco conceptual presentado por el representante especial.

El Consejo, tras el final del mandato de Ruggie, estableció un Grupo de Trabajo ${ }^{6}$ para dar seguimiento a la difusión e implementación de los Principios Rectores, así como para recolectar y compartir las buenas prácticas que existen tanto a nivel estatal como empresarial. Debe decirse, sin embargo, que la ejecución de dicho mandato no ha sido sencilla, en virtud de las importantes diferencias administrativas y políticas en el seno de los Estados, y de la titánica tarea de monitorear la actividad de millones de empresas, nacionales y transnacionales, alrededor del mundo. ${ }^{7}$ Cabe mencionar, sin embargo, que el Grupo de Trabajo ha sabido capitalizar las tendencias más importantes en la materia, como el desarrollo de planes nacionales de acción sobre empresas y derechos humanos, ${ }^{8} \mathrm{o}$ su coordina-

ples”, en Deva, S. y Bilchitz, D. (eds.), Human Rights Obligations of Business: Beyond the Corporate Responsibility to Respect?, Cambridge, Cambridge University Press, 2013, pp. 91-103; Bilchitz, D., "A Chasm Between 'is and 'Ought'? A Critique of the Normative Foundations of the SRSG's Framework and the Guiding Principles”, en Deva, S. y Bilchitz, D. (eds.), Human Rights Obligations of Business: Beyond the Corporate Responsibility to Respect?, Cambridge, Cambridge University Press, 2013, pp. 118-130; Cantú Rivera, H. F., "Empresas y derechos humanos: ¿Hacia una regulación jurídica efectiva o el mantenimiento del status quo?”, Anuario Mexicano de Derecho Internacional, Vol. XIII, 2013, pp. 331-339.

5 Ruggie, J.G., Just Business: Multinational Corporations and Human Rights, Nueva York, W.W. Norton \& Co., 2013, pp. 129-132.

6 Consejo de Derechos Humanos, Los derechos humanos y las empresas transnacionales y otras empresas, A/HRC/RES/17/4 (16 de junio de 2011), §6.

7 Addo, M. K., "El mandato del Grupo de Trabajo sobre empresas y derechos humanos: ideas preliminares”, en Martínez Garza, M. E. y Cantú Rivera, H. F. (comp.), El futuro es hoy: Construyendo una agenda de derechos humanos, Monterrey, CEDHNL/UANL, 2013, pp. 79-83.

8 Grupo de Trabajo sobre la cuestión de los derechos humanos y las empresas transnacionales y otras empresas, A/69/263 (5 de agosto de 2014). Sobre la cuestión de los planes nacionales de acción, véase de forma general De Felice, D. y Graf, A., “The Potential of National Action Plans to Implement Human Rights Norms: An Early Assessment with Respect to the 
Esta revista forma parte del acervo de la Biblioteca Jurídica Virtual del Instituto de Investigaciones Jurídicas de la UNAM

ción y trabajo con las diferentes organizaciones regionales para avanzar la implementación de este tema a través de sus respectivos foros. ${ }^{9}$

A pesar de la creciente implantación de los Principios Rectores de la ONU en diferentes espacios y estructuras, ${ }^{10}$ diversos casos judiciales ${ }^{11} \mathrm{y}$ la lenta actividad gubernamental para conformar sus proyectos políticos y económicos a los estándares internacionales en la materia dieron origen a un nuevo llamado a establecer un marco normativo internacional para regular las actividades de las empresas de carácter transnacional. La capitalización de ese llamado tuvo lugar en 2014, y generó una profunda división entre aquellos Estados en contra de la adopción de un instrumento internacional jurídicamente vinculante, los Estados a favor de dicha propuesta, y numerosos Estados que decidieron no manifestarse al respecto, a pesar de sus claras políticas económicas neoliberales. De tal manera, la búsqueda de crear un tratado internacional en la materia amenaza con romper un consenso que tardó más de cuarenta años en alcanzarse, y al que no se le

UN Guiding Principles on Business and Human Rights”, Journal of Human Rights Practice, vol. 7 (1), 2015.

9 Grupo de Trabajo sobre la cuestión de los derechos humanos y las empresas transnacionales y otras empresas, Informe sobre el Primer Foro Regional de América Latina y el Caribe sobre Empresas y Derechos Humanos, A/HRC/26/25/Add.2 (24 de abril de 2014); Grupo de Trabajo sobre la cuestión de los derechos humanos y las empresas transnacionales y otras empresas, Informe sobre el Primer Foro Regional de África sobre las Empresas y los Derechos Humanos, A/ HRC/29/28/Add.2 (2 de abril de 2015).

10 Incluso se considera que existe en la actualidad un ecosistema internacional sobre empresas y derechos humanos, por su adopción en los marcos jurídicos e institucionales de distintas organizaciones como el Consejo de la Unión Europea, la Comisión Europea, la Organización de Estados Americanos, la Organización para la Cooperación y el Desarrollo Económicos, ASEAN, entre otras.

11 Dos casos en particular resaltaron la dificultad (jurídica o política) para juzgar a las empresas en foros nacionales tanto de países desarrollados como en vías de desarrollo: Kiobel et al. v. Royal Dutch Petroleum Co. et al., 133 S.Ct. 1659 (2013); Sentencia, María Aguinda et al. v. Chevron Corp., Caso núm. 2003-0002, Sala Única de la Corte Provincial de Justicia de Sucumbíos (14 de febrero de 2011). Se ha escrito un número importante de comentarios sobre la sentencia Kiobel: véase “Agora: Reflections on Kiobel”, American Journal of International Law, vol. 107, 2013; Cantú Rivera, H., "The Kiobel Precedent and its Effects on Universal Jurisdiction and the Business \& Human Rights Agenda”, Cuestiones Constitucionales, núm. 30, 2014. Respecto a la sentencia en el caso de Ecuador, véase Cantú Rivera, H., "Towards Judicial Accountability in the Business \& Human Rights Field?”, en Moura Vicente, D. (ed.), Towards a Universal Justice? Putting International Courts and Jurisdictions into Perspective, Leiden, Brill, 2015 (en prensa). 
Esta revista forma parte del acervo de la Biblioteca Jurídica Virtual del Instituto de Investigaciones Jurídicas de la UNAM

ha dado tiempo suficiente para su adecuado desarrollo e implementación a nivel interno. ${ }^{12}$

El presente artículo busca dilucidar el desarrollo que ha seguido la cuestión de la responsabilidad de las empresas en el ámbito de los derechos humanos desde la adopción de los Principios Rectores, y de forma particular la manera en que la polarización entre la adopción de estándares jurídicos vinculantes o instrumentos no vinculantes volvió a instalarse en el seno de esta discusión a nivel internacional. Asimismo, se busca brindar al lector una visión panorámica en torno a la resolución del Consejo de Derechos Humanos de la ONU de crear un Grupo de Trabajo intergubernamental para desarrollar un instrumento jurídicamente vinculante, y los resultados de su primera sesión desde una perspectiva interna.

En ese sentido, la segunda sección del presente artículo se refiere a las propuestas presentadas al Consejo de Derechos Humanos respecto a un instrumento vinculante, por una parte, y a la extensión del mandato del Grupo de Trabajo a cargo de la difusión e implementación de los Principios Rectores, por la otra. Una tercera sección se dedica a analizar los principales temas - tanto positivos como negativos - que deben ser abordados en el marco de una discusión sobre un tratado internacional en la materia. La cuarta sección, por su parte, se concentra en brindar al lector unas breves reflexiones sobre la primera sesión del Grupo de Trabajo intergubernamental de composición abierta para la elaboración de un instrumento internacional jurídicamente vinculante, así como los principales obstáculos y temáticas que fueron abordadas. Finalmente, se presentan unas breves conclusiones sobre lo que se debe esperar para las siguientes sesiones del Grupo de Trabajo intergubernamental.

12 Desde luego, no debe dejarse de lado la indecisión —o tal vez falta de voluntad — de algunos Estados para actuar en este tema a nivel interno, a través de la implementación de reformas políticas, legislativas y judiciales recomendadas por los Principios Rectores. John Ruggie señala que la implementación de cambios en la cultura corporativa puede tomar hasta dos años, y que por lo general los cambios en las políticas gubernamentales tienden a tomar más tiempo. Véase Ruggie, J. G., Just Business: Multinational Corporations and Human Rights, Nueva York, W.W. Norton \& Co., 2013, p. 177. 
Esta revista forma parte del acervo de la Biblioteca Jurídica Virtual del Instituto de Investigaciones Jurídicas de la UNAM

II. LA PROPUESTA DE ECUADOR Y SUDÁFRICA SOBRE UN INSTRUMENTO INTERNACIONAL VINCULANTE, Y EL VOTO DE CONTINUIDAD A LA DIFUSIÓN E IMPLEMENTACIÓN DE LOS PRINCIPIOS RECTORES DE LA ONU SOBRE LAS EMPRESAS Y LOS DERECHOS HUMANOS

La consolidación de los Principios Rectores sobre las empresas y los derechos humanos a nivel internacional, así como la convergencia internacional y regional de distintos actores, organizaciones e instrumentos hacia un ecosistema universal respecto a la conducta empresarial responsable son desarrollos de una trascendencia e impacto innegable en el derecho internacional de los derechos humanos. ${ }^{13}$ De forma general, se logró consensuar posiciones de sectores previamente polarizados (como las organizaciones de la sociedad civil, los gobiernos y las empresas), lo cual permitió establecer un marco normativo internacional - aunque no jurídicamente vinculante - que determinó la existencia de una responsabilidad empresarial de respetar los derechos humanos. ${ }^{14}$

Sin embargo, el lento desarrollo de acciones nacionales para implementar en el marco jurídico interno de los Estados las disposiciones de los Principios Rectores, la inexistencia de estándares internacionales vinculantes, así como el impacto jurídico de diversos casos en ciertos países ${ }^{15}$ llevaron a la reaparición del debate respecto a la necesidad de contar con un instrumento internacional vinculante para regular las actividades de las empresas en el ámbito de los derechos humanos, ante la ineficacia o insuficiencia de los procedimientos judiciales a nivel interno. En ese sentido, la delegación ecuatoriana ante los organismos internacionales comenzó a promover durante la vigésimo cuarta sesión del Consejo de Derechos Humanos, en sep-

13 Respecto a la cuestión de la convergencia regional en la materia, véanse Cantú Rivera, H., "Regional Approaches in the Business \& Human Rights Field”, L'Observateur des Nations Unies, vol. 35, 2013; Cantú Rivera, H., “The United Nations Guiding Principles on Business and Human Rights in the European Union: From Regional Action to National Implementation", en Martin, J. y Bravo, K. E. (eds.), The Business and Human Rights Landscape: Moving Forward, Looking Back, Cambridge, Cambridge University Press, 2015 (en prensa).

14 Sobre lo anterior, véase Jägers, N., "UN Guiding Principles on Business and Human Rights: Making Headway Towards Real Corporate Accountability?", Netherlands Quarterly of Human Rights, Vol. 29(2), 2011, pp. 159-163.

15 Los ya citados Kiobel y Aguinda, entre otros. 
Esta revista forma parte del acervo de la Biblioteca Jurídica Virtual del Instituto de Investigaciones Jurídicas de la UNAM www.juridicas.unam.mx

tiembre de 2013, la necesidad de contar con un instrumento internacional para regular las actividades empresariales ante los impactos negativos que se produzcan en los derechos humanos. ${ }^{16}$

Dicha promoción fue propuesta formalmente por las delegaciones de Ecuador y de Sudáfrica durante la vigésimo sexta sesión de dicho órgano, en junio de 2014. Tras una votación dividida, en donde 20 Estados ${ }^{17}$ votaron a favor, 14 votaron en contra, ${ }^{18}$ y 13 se abstuvieron, ${ }^{19}$ se adoptó la resolución 26/9 por medio de la cual se creó un Grupo de Trabajo intergubernamental de composición abierta, con el mandato de elaborar un instrumento internacional jurídicamente vinculante sobre los derechos humanos y las empresas transnacionales y otras empresas comerciales. ${ }^{20}$

Algunas de las posiciones de los países eran previsibles: los países desarrollados votaron en contra de la resolución, mientras que Rusia, China, India y una parte importante del grupo africano votaron a favor de la resolución. ${ }^{21}$ Sin embargo, hubo una notable tendencia que contravendría a la expectativa de una renovada división binaria entre el norte global y el sur global: la mayoría de los países latinoamericanos, en particular aquellos que se han adherido a las Directrices de la OCDE para Empresas Multinacionales, ${ }^{22}$ se abstuvieron en la votación. De la misma forma, al-

16 República del Ecuador, "Statement on Behalf of a Group of Countries at the 24rd Session of the Human Rights Council”, en http://business-humanrights.org/sites/default/files/me dia/documents/statement-unhrc-legally-binding.pdf (visitado el 28 de julio de 2015).

17 Argelia, Benín, Burkina Faso, China, Congo, Costa de Marfil, Cuba, Etiopía, Rusia, Filipinas, India, Indonesia, Kazajstán, Kenia, Marruecos, Namibia, Pakistán, Sudáfrica, Venezuela y Vietnam.

18 Alemania, Austria, Estados Unidos de América, Estonia, Macedonia, Francia, Irlanda, Italia, Japón, Montenegro, Gran Bretaña, República Checa, Corea y Rumania.

19 Arabia Saudita, Argentina, Botsuana, Brasil, Chile, Costa Rica, Emiratos Árabes Unidos, Gabón, Kuwait, Maldivas, México, Perú y Sierra Leona.

20 Consejo de Derechos Humanos, Elaboración de un instrumento internacional jurídicamente vinculante sobre las empresas transnacionales y otras empresas con respecto a los derechos humanos, A/ $\mathrm{HRC} / \mathrm{RES} / 26 / 9$ (26 de junio de 2014).

21 Para una explicación de los votos formulados, véase Oficina del Alto Comisionado para los Derechos Humanos, "Council extends mandates on extreme poverty, international solidarity, independence of judges, and trafficking in persons" (26 de junio de 2014), en http:// www.ohchr.org/EN/NewsEvents/Pages / DisplayNews.aspx? NewsID =14785\&LangID =E (visitado el 28 de julio de 2015).

22 Argentina, Brasil, Chile, Colombia, Costa Rica, México y Perú se han adherido a las Directrices de la OCDE para Empresas Multinacionales. De ellos, Colombia no era un Estado miembro del Consejo de Derechos Humanos durante la sesión en que se votó la resolución. 
Esta revista forma parte del acervo de la Biblioteca Jurídica Virtual del Instituto de Investigaciones Jurídicas de la UNAM

gunos países del grupo africano y del grupo Asia-Pacífico se abstuvieron. Lo anterior desde luego indica que a pesar de la insistencia en continuar considerando la existencia de un mundo binario, el efecto de la globalización ha acercado a algunos países en vías de desarrollo hacia el modelo de mercado liberal que en la actualidad continúa promoviendo la inversión extranjera y el intercambio de bienes y servicios a nivel mundial, y del cual numerosas empresas de países emergentes con operaciones transnacionales se han beneficiado. ${ }^{23}$

La resolución de la propuesta liderada por Ecuador y Sudáfrica indicó que las dos primeras sesiones del Grupo de Trabajo intergubernamental serían dedicadas a deliberaciones constructivas sobre las perspectivas y áreas que deben cubrirse por el futuro instrumento, y que a partir de la tercera sesión se comenzaría a discutir el proyecto de instrumento propuesto por el presidente-relator del Grupo de Trabajo intergubernamental, que deberá recoger los insumos de las deliberaciones sostenidas durante las primeras dos sesiones..$^{24}$

A la par de la resolución 26/9, el Consejo de Derechos Humanos adoptó por consenso, a propuesta de Argentina, Noruega, Ghana y Rusia, una segunda resolución, a través de la cual extendió el mandato del Grupo de Trabajo de la ONU sobre las empresas y los derechos humanos por un periodo de tres años. ${ }^{25}$ La resolución 26/22 determinó la adopción de nuevas áreas de enfoque para el Grupo de Trabajo, a la par de su encomienda inicial de difundir y promover los Principios Rectores, particularmente centradas en la cuestión de acceso a recursos jurídicos y no jurídicos para la reparación de violaciones de derechos humanos en que la actividad empresarial

23 Incluso, las predicciones macroeconómicas se orientan a que la economía mundial sea sostenida por países emergentes en las siguientes décadas, apoyadas por las actividades de sus empresas: OECD, “Looking to 2060: A GlobalVision of Long-Term Growth”, OECD Economics Department Policy Notes, núm. 15, 2012, pp. 1, 2 y 7. Véase igualmente PricewaterhouseCoopers, TheWorld in 2050:Will the shift in global economic power continue?, 2015, pp. 1-5, en http: / / www.pwc.com/gx/en/issues/the-economy/assets/world-in-2050-february-2015.pdf (visitado el 31 de agosto de 2015).

24 Consejo de Derechos Humanos, Elaboración de un instrumento internacional jurídicamente vinculante sobre las empresas transnacionales y otras empresas con respecto a los derechos humanos, A/ $\mathrm{HRC} / \mathrm{RES} / 26 / 9$ (26 de junio de 2014), §2-3.

25 Consejo de Derechos Humanos, Los derechos humanos y las empresas transnacionales y otras empresas, A/HRC/RES/26/22 (27 de junio de 2014). 
Esta revista forma parte del acervo de la Biblioteca Jurídica Virtual del Instituto de Investigaciones Jurídicas de la UNAM

estuviere involucrada. ${ }^{26}$ En ese sentido, la resolución llama a la exploración de todas las opciones jurídicas y medidas prácticas existentes para mejorar el acceso a mecanismos de reparación por parte de las víctimas, mismo que derivó en una serie de proyectos paralelos sobre rendición de cuentas y acceso a reparación a cargo de la Oficina del Alto Comisionado para los Derechos Humanos. ${ }^{27}$

Una de las principales preocupaciones al haberse adoptado ambas resoluciones fue que el consenso y progreso logrados con la adopción de los Principios Rectores sobre las empresas y los derechos humanos, así como el alineamiento de estándares internacionales relativos a la responsabilidad de las empresas, se diluyeran ante la existencia de un nuevo proyecto para solidificar las obligaciones internacionales de las personas morales con fines de lucro. ${ }^{28}$ Ciertamente, la sombra de las negociaciones multilaterales respecto al fallido proyecto de código de conducta para empresas transnacionale ${ }^{29}$ que se discutió en la ONU entre las décadas de 1970 y 1990, o bien del proyecto de normas de la Subcomisión de la ONU para la Protección y Promoción de los Derechos Humanos, ${ }^{30}$ se cernieron sobre la resolución 26/9 del Consejo de Derechos Humanos. Una pregunta fundamental formulada por las empresas y los Estados desarrollados fue si sería apropiado desviar la atención de la implementación de los Principios Rectores a nivel nacional y regional, en virtud del corto tiempo que ha transcurrido desde su adopción, para comenzar las discusiones en torno al proceso del tratado.

Por otra parte, otra tendencia se desarrolló a favor del carácter complementario de los dos proyectos. Como Surya Deva y John Ruggie, dos de los principales expertos en el tema, lo han propuesto, resulta innecesario e im-

26 Ibidem $\$ 9$.

27 Ibidem $\$ 7$. Dicha iniciativa (Initiative on enhancing accountability and access to remedy in cases of business involvement in human rights abuses) puede ser consultada en http://www.ohchr. org/EN/Issues / Business / Pages/OHCHRstudyondomesticlawremedies.aspx (visitado el 28 de julio de 2015).

28 Véase por ejemplo Ruggie, J., Quo Vadis? Unsolicited Advice to Business and Human Rights Treaty Sponsors (9 de septiembre de 2014), disponible en http: / /www.ihrb.org/commentary/quovadis-unsolicited-advice-business.html (visitado el 28 de julio de 2015).

29 UN Draft Code of Conduct on Transnational Corporations, E/1988/39/Add.1 (1o. de febrero de 1988).

30 Subcomisión de Promoción y Protección de los Derechos Humanos, Normas sobre las responsabilidades de las empresas transnacionales y otras empresas comerciales en la esfera de los derechos humanos, E/CN.4/Sub.2/2003/12/Rev.2 (26 de agosto de 2003). 
Esta revista forma parte del acervo de la Biblioteca Jurídica Virtual del Instituto de Investigaciones Jurídicas de la UNAM

productivo observar el fenómeno de la responsabilidad empresarial desde la dicotomía de la adopción de estándares voluntarios o vinculantes, ya que es necesario contar con un régimen que se oriente a proponer soluciones pragmáticas y que supere conjuntamente las limitaciones individuales de cada uno de los tipos de estándares. ${ }^{31}$ Es decir, es necesario contar tanto con estándares vinculantes - que establezcan las normas aplicables a nivel internacional y que equilibren las diferencias regulatorias entre paísescomo con lineamientos o normas no vinculantes que orienten y permitan a sus destinatarios adaptar sus procesos internos para hacer frente a los impactos en los derechos humanos. Como se puede observar, la utilización de los Principios Rectores sobre las empresas y los derechos humanos en tanto se sientan las bases para la adopción de un tratado internacional en la materia no sólo es una idea lógica, sino complementaria y que puede permitir generar consensos y desarrollos jurídicos y prácticos que favorezcan la protección de las víctimas de violaciones a los derechos humanos. ${ }^{32}$

En principio, las dos resoluciones no son contradictorias, sino que se complementan mutuamente: la resolución 26/9 contiene sendas referencias a los primeros dos pilares de los Principios Rectores (la obligación del Estado de proteger los derechos humanos, y de la empresa de respetarlos), mientras que la resolución 26/22 enfatiza la necesidad de concentrar el trabajo de la Oficina del Alto Comisionado para los Derechos Humanos y del Grupo de Trabajo sobre las empresas y los derechos humanos en el tercer pilar, particularmente a través del Proyecto sobre rendición de cuentas y mecanismos de reparación, por una parte, y de la exploración de las

31 Surya Deva llama a su proyecto una "teoría integrada de regulación" (integrated theory of regulation), mientras que John Ruggie denomina al suyo una "mezcla inteligente de medidas" (smart mix of measures); aunque difieren en algunos puntos, ambos sugieren que los instrumentos no vinculantes, aparejados con medidas obligatorias a nivel interno (y eventualmente a nivel internacional), con la adecuada vigilancia o monitoreo de sociedad civil y autoridades, pueden lograr un comportamiento responsable de las empresas en el ámbito de los derechos humanos. Sobre estos puntos, véanse Ruggie, J. G., Just Business: Multinational Corporations and Human Rights, Nueva York, W.W. Norton \& Co., 2013, p. xxiii, 125; Deva, S., Regulating Corporate Human RightsViolations: Humanizing Business, Londres, Routledge, 2012, p. 193.

32 Darcy, S., “A New Business and Human Rights Instrument?”, p. 2, artículo presentado durante la sesión de lluvia de ideas sobre empresas y derechos humanos titulada Access to Justice and Extraterritorial Obligations, del 26 de febrero de 2015 en Ginebra, en http:// www.fes-globalization.org/geneva/documents/2015/2015_2_26_Darcy_Contribution\%20to\%20 Roundtable\%20-\%20Geneva.pdf (visitado el 28 de julio de 2015). 
Esta revista forma parte del acervo de la Biblioteca Jurídica Virtual del Instituto de Investigaciones Jurídicas de la UNAM www.juridicas.unam. $\mathrm{mx}$

diversas medidas para garantizar el acceso a recursos jurídicos efectivos, por la otra.

En ese sentido, el proyecto sobre el tratado necesariamente deberá tomar en consideración el contenido de los Principios Rectores, que desde sus orígenes ha sido concebido como una plataforma sobre la que puede desarrollarse el andamiaje jurídico sobre el tema a nivel internacional. Ciertamente la presión y expectativa internacional en torno a este proyecto jurídico es alta, por lo que se espera que este instrumento tome en consideración diversos elementos cuya característica común es su carácter controversial a la luz del derecho internacional. A esta cuestión se dedican los párrafos sucesivos.

\section{POSIBILIDADES Y DESAFÍOS DE UN TRATADO INTERNACIONAL SOBRE LA RESPONSABILIDAD EMPRESARIAL EN EL ÁMBITO \\ DE LOS DERECHOS HUMANOS}

Diversas cuestiones deben ser abordadas al momento de comenzar a reflexionar sobre la viabilidad y posibilidad de desarrollar un tratado internacional sobre la responsabilidad de las empresas en el ámbito de los derechos humanos. Sin embargo, este tema resalta por la necesidad de discutir sobre temas jurídicos que continúan siendo controversiales, como la competencia jurisdiccional, el sujeto obligado, las conductas a regular, los conflictos o jerarquía de normas a nivel internacional o los mecanismos de investigación y reparación a nivel internacional, entre otros. Debido a su profundidad y complejidad, los siguientes párrafos se limitarán a discutir de forma sucinta los principales desafíos y las posibilidades en la adopción de un instrumento internacional jurídicamente vinculante, buscando sin embargo dilucidar las principales posiciones existentes en torno a los temas señalados.

Un punto inicial a considerar es que, bajo el derecho internacional, todo lo que no está prohibido está permitido. ${ }^{33}$ Esa regla no escrita, frecuentemente invocada en el ámbito del ejercicio extraterritorial de la

33 Lo anterior fue señalado por la Corte Permanente de Justicia Internacional en 1927: PCIJ, The Case of the S.S. Lotus (France v. Turkey), serie A, núm. 10, 7 de septiembre de 1927, p. 18. 
Esta revista forma parte del acervo de la Biblioteca Jurídica Virtual del Instituto de Investigaciones Jurídicas de la UNAM

competencia, ${ }^{34}$ permite considerar la posibilidad de desarrollar un tratado bajo el derecho internacional de los derechos humanos que se centre en regular las actividades de sujetos no estatales, en este caso las empresas con operaciones transnacionales. En principio no existe ninguna barrera jurídica para ello bajo el derecho internacional, por lo que se ha considerado que las limitaciones que han existido para tal proyecto han sido particularmente de índole política o comercial. ${ }^{35} \mathrm{Al}$ ser sujetos de derecho interno, en principio el desarrollo de obligaciones jurídicas directas de carácter internacional sobre las empresas no encontraría mayor obstáculo (jurídico) que la conciliación de las posiciones políticas de los diferentes Estados. Incluso algunos tratados internacionales, como el Convenio internacional sobre responsabilidad civil por daños causados por la contaminación de las aguas del mar por hidrocarburos, ${ }^{36}$ han establecido obligaciones jurídicas directas en materia de reparación a cargo de las empresas, en donde el papel del Estado se ve (relativamente) reducido a asegurar la existencia de un foro adecuado y a regular los fondos de reparación que deben ser puestos a disposición por las empresas en caso de contaminación por hidrocarburos.

No obstante, no debe ignorarse el hecho de que este caso es bastante lejano al ámbito de los derechos humanos, un área tradicionalmente centrada en las obligaciones de los Estados, y que incluso en ámbitos más cercanos como en el caso de la Organización Internacional del Trabajo, los instrumentos internacionales señalan repetidamente las obligaciones de los Es-

34 Bernaz, N., “'Enhancing Corporate Accountability for Human Rights Violations: Is Extraterritoriality the Magic Potion?”, Journal of Business Ethics, vol. 117 (3), 2013, p. 508; Lenhoff, A., "International Law and Rules on International Jurisdiction", Cornell Law Review, vol. 50, 1964, pp. 5-7; Inazumi, Mitsue, Universal Jurisdiction in Modern International Law: Expansion of National Jurisdiction for Prosecuting Serious Crimes under International Law, Cambridge, Intersentia, 2005, pp. 23-30.

35 Pitts, Ch., "For a Treaty on Business \& Human Rights", p. 2, artículo presentado en el seminario Does the World Need a Treaty on Business and Human Rights? Weighing the Pros and Cons, organizado por la Escuela de Derecho de la Universidad de Notre Dame y el Centro de Información sobre Empresas y Derechos Humanos en Londres, el 14 de mayo de 2014. El autor hizo énfasis en la inexistencia de barreras jurídicas para desarrollar un tratado en la materia durante sus participaciones como panelista experto en la primera sesión del Grupo de Trabajo intergubernamental.

36 International Convention on Civil Liability for Oil Pollution Damage, UNTS, vol. 973, 1975 , p. 2. 
Esta revista forma parte del acervo de la Biblioteca Jurídica Virtual del Instituto de Investigaciones Jurídicas de la UNAM

tados de asegurar la debida aplicación del tratado respectivo. ${ }^{37}$ Además de ello, los tratados internacionales de derechos humanos que existen en la actualidad establecen que las acciones de actores no estatales darán origen a una responsabilidad indirecta del Estado, con motivo de su omisión de asegurar el respeto de los derechos humanos protegidos por el instrumento en su territorio. ${ }^{38}$ Sin embargo, ningún instrumento internacional de derechos humanos en vigor establece obligaciones jurídicas directas a ser implementadas por las empresas para salvaguardar o respetar los derechos que pudieran ser infringidos por sus operaciones. ${ }^{39}$

Otro argumento que resulta relevante destacar aquí es que los tratados internacionales de derechos humanos en vigor se han concentrado en identificar el acto que debe ser regulado (o protegido) por el Estado parte del instrumento, sin enumerar las categorías de actores no estatales que tendrían la obligación jurídica de respetar o no infringir los derechos protegidos por el instrumento respectivo, ni la manera de garantizar la adopción de acciones que aseguren dicho respeto. ${ }^{40}$ En ese sentido, un tratado internacional en la materia podría ser innovador al establecer una obligación jurídica específica sobre una categoría (relativamente) específica de actores no estatales, ${ }^{41}$ aunque corre el riesgo de ser percibido como un ejercicio

37 López, C., "International Talks on a Treaty on Business \& Human Rights: A Good Start to a Bumpy Road”, 2015, en http://business-humanrights.org/en/international-talks-on-a-treaty-onbusiness-human-rights-a-good-start-to-a-bumpy-road (visitado el 28 de julio de 2015).

38 Véanse de Frouville, O., "Attribution of Conduct to the State: Private Individuals”, en Crawford, J. et al. (eds.), The Law of International Responsibility, Oxford, Oxford University Press, 2010; Latty, F., “Actions and Omissions”, en Crawford, J. et al. (eds.), The Law of International Responsibility, Oxford, Oxford University Press, 2010. Véase igualmente De Schutter, O., "La responsabilité des États dans le contrôle des sociétés transnationales: vers une convention internationale sur la lutte contre les atteintes aux droits de l'homme commises par les sociétés transnationales”, en Decaux, E. (ed.), La responsabilité des entreprises multinationales en matière de droits de l'homme, Bruselas, Bruylant, 2010, p. 47.

39 Las referencias más directas se encuentra en los artículos 2(e) de la CEDAW y 1(e) de la Convención sobre Personas con Discapacidad, en donde se indica que el Estado deberá asegurar la eliminación de patrones de discriminación en las empresas privadas.

40 Por lo general, la mayoría de los tratados se han referido a terceros que actúen con el consentimiento o aquiescencia del gobierno, estableciendo por tanto la obligación de los Estados de adoptar medidas de derecho interno para prevenir las violaciones a los derechos humanos por actores no estatales.

41 Para una perspectiva específica sobre esta cuestión, se recomienda al lector consultar de manera general la obra de Černič, J. L. y Van Ho, T. (eds.), Human Rights and Business: Direct Corporate Accountability for Human Rights, Nijmegen, Wolf Legal Publishers, 2015. 
Esta revista forma parte del acervo de la Biblioteca Jurídica Virtual del Instituto de Investigaciones Jurídicas de la UNAM

diametralmente opuesto a la práctica habitual de los Estados en el ámbito de los derechos humanos.

Un segundo aspecto positivo para la determinación de estándares internacionales que normalicen (con la debida ratificación por los Estados) el marco regulatorio para las empresas en el ámbito de los derechos humanos es el dinamismo e impulso que este tema ha adquirido en la agenda internacional. El proyecto del tratado ha sido apoyado por numerosas organizaciones no gubernamentales (a través de la denominada "Alianza por el Tratado"), ${ }^{42}$ así como por una cantidad significativa de Estados en vías de desarrollo, en lo que parece ser una continuación lógica y razonable tras la adopción de los Principios Rectores sobre las empresas y los derechos humanos en 2011, y de las acciones adoptadas a nivel regional en Europa y América. Por ello, ante la convergencia de diferentes procesos internacionales en donde la participación e involucramiento del sector privado cobra mayor relevancia, este tema se vislumbra como uno de los espacios que permanecerá en la agenda internacional en las siguientes décadas.

A pesar de ello, existen varios aspectos que por su complejidad técnica constituyen desafíos que deberán ser debidamente analizados, discutidos y tomados en cuenta por los Estados que participen en las negociaciones sobre el proyecto de tratado. El primero de ellos es la cuestión de la competencia jurisdiccional, que tiene una relevancia particular en el marco actual de los litigios transnacionales por impactos en los derechos humanos como resultado de la actividad de las empresas. ${ }^{43}$ Tal situación aparece con cierta frecuencia en los contextos en que las empresas con operaciones transnacionales generan un impacto negativo en los derechos humanos de las personas o comunidades del sitio donde operan; ante ello, surge la problemática para las víctimas de acudir a un foro judicial que pueda recibir sus reclamos. Sin embargo, como se ha podido observar en diversos casos

42 Movimiento Global por un Tratado Vinculante, http: / / www.treatymovement.com / alianzapara-el-tratado/.

43 Numerosos estudios han sido preparados sobre este tema en el contexto de las empresas y los derechos humanos. Véanse inter alia De Schutter, O., "Les affaires Total et Unocal: Complicité et extraterritorialité dans l'imposition aux entreprises d'obligations en matière de droits de l'homme", Annuaire français de droit international, 2006; De Schutter, O., Extraterritorial Jurisdiction as a tool for improving the Human Rights Accountability of Transnational Corporations (22 de diciembre de 2006); Bucher, A., "La compétence universelle civile", Recueil des cours, vol. 372, 2015. 
Esta revista forma parte del acervo de la Biblioteca Jurídica Virtual del Instituto de Investigaciones Jurídicas de la UNAM

judiciales recientes, los Estados receptores de inversión por lo general no tienen la posibilidad o la voluntad de dirimir casos en que empresas con operaciones transnacionales hayan estado implicadas (directamente o por complicidad) en violaciones a los derechos humanos. ${ }^{44}$

Ante el riesgo de denegación de justicia en el Estado receptor, las víctimas en ocasiones presentan sus demandas en los Estados de origen de las empresas, ${ }^{45} \mathrm{o}$ bien en foros en donde las leyes nacionales propician la utilización de sus tribunales como foros con competencia universal, como los Estados Unidos de América. ${ }^{46}$ No obstante, la práctica reciente se ha inclinado a limitar el ejercicio de dicha competencia universal (o extraterritorial) por los tribunales de Estados con pocos o nulos nexos con el caso en cuestión, en un esfuerzo por reducir las fricciones diplomáticas (particularmente con aquellos Estados en donde se encuentren registradas las empresas matrices), aunque también de limitar la concentración de litigios sin relación con la jurisdicción. ${ }^{47}$ Desde luego, ante la incapacidad o desinterés de ciertos Estados por admitir a trámite dichos casos, las víctimas sufren la violación de otro de sus derechos humanos, el derecho a un recurso judicial efectivo.

El proyecto de tratado deberá, considerando la práctica actual en la materia, buscar proponer soluciones efectivas a esta situación. Una situación ideal incluiría un fortalecimiento de las capacidades institucionales de los Estados receptores de inversión para tener la capacidad técnica y jurídica de dirimir las controversias ocurridas en su territorio, lo cual procesalmente y desde una perspectiva probatoria sería lo más sencillo. No obstante, en aquellos casos en que los Estados receptores no puedan (o no quieran, a

44 Desde luego, la principal referencia en la actualidad es respecto al caso de Chevron en el Ecuador, citado supra. En muchas ocasiones, dicha reticencia deriva de la influencia que tiene la presencia de la empresa en el Estado como resultado de su impacto económico positivo, o bien, por la amenaza de que las empresas comiencen un litigio arbitral contra el Estado con base en acuerdos bilaterales de inversión que potencialmente podrían ser muy costosos.

45 Véase al respecto McCorquodale, R., "Waving Not Drowning: Kiobel Outside the United States”, American Journal of International Law, vol. 107, 2013, pp. 846 y 847, quien presenta el caso de los países europeos a la luz de los Reglamentos Bruselas I y Roma II.

46 Pérez Correa Camarena, F., "El Alien Tort Statute: El imperialismo judicial de los valores occidentales”, Revista de la Facultad de Derecho de México, núm. 260, 2013.

47 Esto ha sido resultado directo del caso Kiobel citado supra. Véase de forma general Cantú Rivera, H., "The Kiobel Precedent and its Effects on Universal Jurisdiction and the Business \& Human Rights Agenda”, Cuestiones Constitucionales, núm. 30, 2014. 
Esta revista forma parte del acervo de la Biblioteca Jurídica Virtual del Instituto de Investigaciones Jurídicas de la UNAM

pesar de quebrantar sus obligaciones de derechos humanos) dar trámite a dichos reclamos, el tratado podría establecer una competencia subsidiaria para los Estados de origen de las empresas, con la finalidad de que ejerzan su competencia jurisdiccional en aquellos casos en que empresas de su nacionalidad (o sus filiales en el extranjero) estén involucradas en violaciones a los derechos humanos. ${ }^{48}$ El vínculo generador de la competencia, por tanto, sería la "nacionalidad" de la empresa (es decir, aquél lugar donde se haya constituido o donde se encuentre su sede principal de operaciones), con lo que se establecería un orden de competencia que permitiría resolver ciertos conflictos derivados de la elección de jurisdicción. ${ }^{49}$

Asimismo, en casos de violaciones graves a los derechos humanos y ante la falta de ejercicio de la jurisdicción por los Estados receptor o de origen de las empresas, se podría prever la habilitación de una "tercera" jurisdicción por necesidad (forum necessitatis) que permitiera a las víctimas comparecer a exponer sus reclamos y demandas. ${ }^{50}$ Claramente, el uso de esa "tercera” jurisdicción debe limitarse al máximo posible y ser excepcional, en virtud de su carácter polémico y de la oposición que pudiera surgir por parte de los Estados de origen o recepción de las empresas; para ello, será necesario definir de forma precisa lo que se entiende por "violación grave", así como determinar los candados necesarios para evitar una utilización abusiva.

48 Sobre esta posibilidad, véase De Schutter, O., "La responsabilité des États dans le contrôle des sociétés transnationales: vers une convention internationale sur la lutte contre les atteintes aux droits de l'homme commises par les sociétés transnationales", en Decaux, E. (ed.), La responsabilité des entreprises multinationales en matière de droits de l'homme, Bruselas, Bruylant, 2010, p. 90.

49 Dicha postura ha sido adoptada, por ejemplo, por el Protocolo facultativo de la Convención sobre los Derechos del Niño relativo a la venta de niños, la prostitución infantil y la utilización de niños en la pornografía (el vínculo de nacionalidad está contemplado en el artículo 4.2, y conforme al artículo 3.4, podrá incluir a personas jurídicas); o bien, ha sido utilizado en el contexto de los Puntos de Contacto Nacional en el marco de las Directrices para Empresas Multinacionales de la Organización para la Cooperación y el Desarrollo Económico. Sobre este último punto, véase Cantú Rivera, H., "La OCDE y los derechos humanos: el caso de las Directrices para Empresas Multinacionales y los Puntos de Contacto Nacional”, Anuario Mexicano de Derecho Internacional, vol. XV, 2015, pp. 642 y 643.

50 Bucher, A., 'La compétence universelle civile', Recueil des cours, vol. 372, 2015, pp. 103-106; Redfield, S., "Searching for Justice: The Use of Forum Necessitatis", Georgetown Journal of International Law, vol. 45, 2014, pp. 906-915. 
Esta revista forma parte del acervo de la Biblioteca Jurídica Virtual del Instituto de Investigaciones Jurídicas de la UNAM

En este contexto de la competencia jurisdiccional deberá abordarse igualmente la cuestión de la asistencia o cooperación judicial entre países en casos que involucren impactos en los derechos humanos como resultado de la actividad de las empresas, ${ }^{51}$ a fin de favorecer que los casos puedan tramitarse con la menor cantidad de complicaciones posibles. Lo anterior será igualmente necesario para la cuestión de la ejecución de los fallos, con la debida adopción de medidas para asegurar que las sentencias a ejecutarse cumplan con los principios de respeto al orden público, al debido proceso y a la transparencia.

Un segundo tema que debería ser analizado en el marco de las discusiones a sostenerse por el Grupo de Trabajo intergubernamental es definir quién sería el sujeto obligado por el tratado. De forma común, se hace referencia a los impactos en los derechos humanos en el contexto de las operaciones de las empresas transnacionales. Sin embargo, ¿qué es una empresa transnacional? En realidad, ese término ha sido adoptado para referirse a los grupos de personas jurídicas de distintas nacionalidades que, bajo un nombre o marca común y a través de distintas estructuras corporativas, trabajan de forma coordinada en diferentes jurisdicciones. ${ }^{52}$ De forma estricta, las empresas "transnacionales" no existen en el ámbito jurídico, por lo que adoptar un tratado internacional para regularlas parecería un ejercicio sin una finalidad clara. En todo caso, podría ser más efectiva la adopción de un instrumento internacional dirigido a regular las conductas de las empresas que generen impactos negativos en los derechos de las personas, que a regular a los entes jurídicos en sí. Volvemos, pues, a la discusión abierta previamente sobre la necesidad de regular el acto violatorio en vez de al actor, aunque en el marco de la presente discusión existiría una delimitación clara en torno a las actividades realizadas por las personas jurídicas.

Como se puede observar, nuestra posición se inclina a favor de que en un eventual instrumento internacional se busque regular las actividades

51 Lo anterior fue incluso propuesto por la Misión del Ecuador en la nota conceptual preparada para la primera sesión del Grupo de Trabajo. Véase Misión Permanente del Ecuador ante la ONU y otros Organismos Internacionales, Concept note proposed under the responsibility of the designated Chair, Amb. María Fernanda Espinosa, Permanente Representative of Ecuador to the United Nations in Geneva, §5, disponible en http://www.ohchr.org/EN/HRBodies/HRC/ WGTransCorp/Pages/Session1.aspx (visitado el 28 de julio de 2015).

52 Sobre este punto, véase Clapham, A., Human Rights Obligations of Non-State Actors, Oxford, Oxford University Press, 2006, pp. 199-201. 
Esta revista forma parte del acervo de la Biblioteca Jurídica Virtual del Instituto de Investigaciones Jurídicas de la UNAM

de las empresas de forma general, independientemente de que sus operaciones tengan carácter transnacional o meramente doméstico, ya que ante el impacto en los derechos humanos (y en la percepción de las víctimas) dicho carácter resulta irrelevante. Sin embargo, como lo ha propuesto la Federación Internacional de los Derechos Humanos (FIDH) y la Alianza por el Tratado, un enfoque especial deberá darse también a los casos en donde la empresa tenga operaciones transnacionales, ante el incremento de la posibilidad de evadir la competencia de las diversas jurisdicciones donde opera. ${ }^{53}$ Si bien podría parecer una discusión semántica, en el marco de la primera sesión del Grupo de Trabajo intergubernamental esta situación generó una importante confrontación entre los diversos Estados presentes. Dicha situación será abordada, sin embargo, en la siguiente sección.

Un tercer punto de marcada relevancia en este tema es la cuestión de la materia a regular, en el sentido de si el instrumento debe enfocarse en las violaciones más graves a los derechos humanos, o bien, si debe ampliarse a la protección de todos los derechos humanos internacionalmente reconocidos. Algunos se han inclinado por una posición pragmática y factible, sugiriendo la adopción de un tratado que se refiera exclusivamente a las violaciones graves de derechos humanos, ante la aceptación universal de la necesidad de prohibir o perseguir dichas conductas. ${ }^{54}$ Lo anterior sería en principio más sencillo de acordar debido al reconocimiento de que las violaciones graves de derechos humanos que puedan constituir crímenes internacionales gozarían de la aceptación prácticamente incondicional de los Estados, como se ha acordado ya en materia penal.

Sin embargo, los impactos de las empresas por lo general no son respecto a violaciones graves, como torturas, ejecuciones extrajudiciales o desapariciones forzadas, sino a otro tipo de conductas o actividades que impactan en los derechos económicos o sociales de la población (como en la salud, el trabajo, al agua o la alimentación), y que por tanto generan impactos importantes en el derecho a la vida. Asimismo, la adopción de un

53 Grupo de trabajo intergubernamental de composición abierta sobre las empresas transnacionales y otras empresas con respecto a los derechos humanos, Joint Written Statement Submitted by FIDH,Tides Center Project, ESCR-Net, non-Governmental Organizations with Special Consultative Status, A/HRC/WG.16/1/NGO/7 (24 de junio de 2015), p. 5.

54 Ruggie, J. G., “A UN Business and Human Rights Treaty? An Issues Brief”, p. 5, en http: / / business-humanrights.org/sites / default/files/media/documents/ruggie-on-un-business-hu man-rights-treaty-jan-2014.pdf. 
Esta revista forma parte del acervo de la Biblioteca Jurídica Virtual del Instituto de Investigaciones Jurídicas de la UNAM www.juridicas.unam.mx

tratado sobre un espectro reducido de derechos podría sugerir la existencia de una jerarquía entre los diferentes derechos y libertades de los seres humanos, situación que sería incompatible con el carácter interrelacionado, interdependiente e indivisible que estos guardan. En ese sentido, un tratado con un enfoque minimalista podría resultar perjudicial para la protección global de los derechos humanos, lo cual indudablemente constituiría un retroceso a pesar de la viabilidad política de lograr tal acuerdo.

Un cuarto tema que tiene una importante relevancia para las discusiones del tratado es la jerarquía de las normas en el derecho internacional. ${ }^{55}$ En el ámbito de las empresas y los derechos humanos, dos conjuntos normativos destacan por su contraposición: las normas o acuerdos de inversión a nivel internacional, por un lado, y los tratados de derechos humanos, por el otro. ${ }^{56}$ De manera general, los tratados bilaterales de inversión buscan brindarle seguridad jurídica a los Estados contratantes respecto a la normatividad aplicable a las inversiones realizadas en un territorio determinado, además de garantizar al inversionista ciertas condiciones de trato que tienden a beneficiar sus intereses. Sin embargo, diversos casos en América Latina (y en otras regiones del mundo) han demostrado que la utilización de cláusulas de estabilización ${ }^{57}$ nulifican el poder del Estado e impiden una

55 Sobre la jerarquía normativa en el derecho internacional, véanse de forma general Shelton, D., "Normative Hierarchy in International Law", American Journal of International Law, vol. 100, 2006; De Wet, E. y Vidmar, J., "Conflicts Between International Paradigms: Hierarchy versus Systemic Integration”, Global Constitutionalism, vol. 2 (2), 2013; Hirsch, M., "Interactions Between Investment and Non-investment Obligations" in Muchlinski, P., Ortino, F. y Schreuer, Ch. (ed.), The Oxford Handbook of International Investment Law, Oxford, Oxford University Press, 2008.

56 Se ha desarrollado una interesante y abundante línea doctrinal sobre este tema. Véanse en particular Dupuy, P. M. et al. (eds.), Human Rights in International Investment Law and Arbitration, Oxford, Oxford University Press, 2009; Suda, R., "The Effect of Bilateral Investment Treaties in Human Rights Enforcement and Realization”, en De Schutter, O. (ed.), Transnational Corporations and Human Rights, Oxford, Hart, 2006; Karamanian, S. L., "The Place of Human Rights in Investor-State Arbitration”, Lewis \& Clark Law Review, vol. 17 (2), 2013, pp. 432-447.

57 Las cláusulas de estabilización son disposiciones incluidas en los tratados de inversión que tienden a garantizar al inversionista que las reglas acordadas en el instrumento bilateral no serán modificadas por eventuales reformas legislativas o regulatorias por parte del Estado receptor. En sí, tienden a "congelar" el poder regulatorio del Estado, ante el riesgo de usualmente costosos litigios ante tribunales arbitrales internacionales. Sobre las cláusulas de estabi- 
Esta revista forma parte del acervo de la Biblioteca Jurídica Virtual del Instituto de Investigaciones Jurídicas de la UNAM

adecuada y efectiva protección de los derechos humanos en las áreas en que la inversión está protegida. ${ }^{58}$

Uno de los principales impedimentos para que el Estado ejerza libremente su capacidad regulatoria (en el marco de su soberanía) a pesar de los tratados de inversión radica en el riesgo de ser demandados ante tribunales arbitrales constituidos para la solución de controversias entre Estado e inversionista. De forma usual, los laudos arbitrales han resultado particularmente costosos para los Estados, a pesar de la presentación de argumentos sobre normativas contendientes que prevén, por un lado, la protección de las inversiones extranjeras, y por otro, la protección de los derechos humanos de la población. ${ }^{59}$ No obstante, la práctica arbitral raramente ha tomado en consideración las disposiciones aplicables de derechos humanos a la disputa arbitral, en virtud de usualmente encontrarse fuera del ámbito de competencia ratione materiae del tribunal, que por lo general tiene competencia sobre las normas determinadas en el acuerdo de inversión y que excluyen otras obligaciones contrapuestas que tiene el Estado.

Ante la frecuente imposibilidad de los Estados en vías de desarrollo de cumplir con sus obligaciones de derechos humanos con motivo de sus acuerdos de inversión, se ha comenzado a pugnar por el establecimiento de una jerarquía normativa a nivel internacional que reconozca la primacía de los derechos humanos frente a otras normas internacionales, incluyendo en el marco del Grupo de Trabajo intergubernamental. Teóricamente, no habría impedimento para establecer que los derechos humanos deben ser respetados aún en el contexto de obligaciones contrapuestas que han sido igualmente adquiridas por los Estados en el marco de su soberanía. ${ }^{60}$ Sin

lización, véase Morgera, E., Corporate Accountability in International Environmental Law, Nueva York, Oxford University Press, 2009, p. 27.

58 Un claro ejemplo en América Latina ha sido el derecho al agua; véase al respecto Meshel, T. "Human Rights in Investor-State Arbitration:The Human Right to Water and Beyond", Journal of International Dispute Settlement, vol. 6 (2), 2015, pp. 281-301.

59 Véanse por ejemplo CIADI, Compañía de Aguas del Aconquija, S.A. et al. c. República Argentina, Caso No. ARB/97/3 (Laudo, 2007), §§3.3.2-3.3.6; CIADI, Suez, Sociedad General de Aguas de Barcelona, S.A. et al. c. República Argentina, Caso No. ARB/03/19 (Decisión sobre responsabilidad, 2010), §§251, 254; ambos laudos fueron por cientos de millones de dólares, a favor de las empresas.

60 Cfr. Jurisdictional Immunities of the State (Germany v. Italy; Greece intervening), Judgment, I.C.J. Reports 2012, p. 99, donde la Corte consideró que la inmunidad jurisdiccional tenía preponderancia ante los derechos humanos de las víctimas. 
Esta revista forma parte del acervo de la Biblioteca Jurídica Virtual del Instituto de Investigaciones Jurídicas de la UNAM

embargo, los aspectos prácticos para la elaboración o implementación de tal jerarquía son particularmente complejos. Para comenzar, ¿qué legitimidad existe a nivel internacional para que un tratado sobre derechos humanos tenga primacía frente a diversos instrumentos bilaterales de inversión, particularmente si los Estados parte de éstos no acordaron dicha primacía en los respectivos instrumentos? ¿Qué ocurriría si un Estado parte de un tratado de inversión no lo es en un instrumento de derechos humanos que pretenda establecer dicha jerarquía normativa a nivel internacional? Y en su caso, ¿qué garantía existe de que tal declaración en un instrumento internacional vinculante será aplicada por mecanismos de solución de controversias de otros ámbitos normativos del derecho internacional, en particular por los tribunales arbitrales de inversión? Como se desprende de estas preguntas, la relativa simplicidad teórica de establecer una jerarquía jurídica internacional enfrenta numerosas aristas al momento de comenzar a reflexionar sobre su implementación.

Desde una perspectiva práctica, la mejor forma de lograr ese equilibrio entre derechos humanos y derechos de los inversionistas ocurriría a través de la renegociación de los tratados bilaterales de inversión existentes, de forma que se inserte una cláusula convencional que establezca una excepción regulatoria a favor del Estado para aquellos casos que pudieran generar impactos negativos en los derechos humanos por parte de los inversionistas. Lo mismo ocurriría con los tratados que aparezcan en el futuro, donde de mucha conveniencia sería contar con una evaluación previa a la ratificación del instrumento para medir los posibles impactos en la capacidad regulatoria del Estado y, por consecuencia, en su capacidad de protección de los derechos humanos. ${ }^{61}$ Sin embargo, su concretización dependerá de la voluntad política que exista entre los Estados, lo cual desde luego puede resultar problemático ante la posibilidad de reducir la protección jurídica de las inversiones de empresas provenientes de países desarrollados. El tema de las inversiones y los derechos humanos es, sin lugar a dudas, uno de los espacios de discusión más complejos que estarán en la agenda del Grupo de Trabajo intergubernamental sobre el tratado, y

61 Véase Simma, B., "Foreign Investment Arbitration: A Place for Human Rights?", International and Comparative Law Quarterly, vol. 60, 2011, pp. 594-596, quien propone una evaluación de impacto en derechos humanos previa a la suscripción de instrumentos internacionales de inversión. 
Esta revista forma parte del acervo de la Biblioteca Jurídica Virtual del Instituto de Investigaciones Jurídicas de la UNAM

que seguramente merecerán la intervención de especialistas de las distintas ramas del derecho internacional.

Finalmente, uno de los principales temas que tendrá una importancia trascendental en las discusiones del Grupo de Trabajo intergubernamental será la cuestión de la implementación y monitoreo de cumplimiento del instrumento que llegase a ser adoptado. De forma particular, esta cuestión necesitará de profundas reflexiones si se desea en realidad crear un instrumento que tenga un impacto verdadero en la protección de los derechos humanos de las personas más desfavorecidas. ${ }^{62}$ Los nueve tratados internacionales de derechos humanos adoptados hasta la fecha han instituido comités para monitorear la implementación de los estándares adoptados por los Estados, en muchos casos teniendo la oportunidad de recibir quejas individuales de individuos que consideren que sus derechos bajo un tratado en cuestión han sido violados. Asimismo, dichos órganos de tratado tienen la posibilidad de desarrollar una interpretación "oficial" del instrumento que lo creó, bajo la figura de observaciones generales. No obstante, a pesar de la competencia de recibir comunicaciones y de monitorear la implementación de las convenciones por los Estados, la efectividad de estos instrumentos es relativa en virtud de la incapacidad de garantizar el estricto cumplimiento y cooperación por los Estados parte. Sin embargo, no se vislumbran alternativas a este modelo con el respaldo político suficiente a nivel internacional para poder crear un sistema de monitoreo más efectivo.

En ese sentido, la determinación de cómo vigilar el cumplimiento del instrumento internacional vinculante que llegase a ser adoptado dependerá en gran medida de la determinación que sea acordada en cuanto a su contenido. Si bien la sociedad civil ha pugnado por un órgano con competencia para exigir a las empresas el cumplimiento de obligaciones jurídicas directas (lo cual sería una novedad en el derecho internacional de los derechos humanos), lo más probable es que el instrumento imponga obligaciones a los Estados de garantizar el respeto de los derechos humanos por las

62 Desde hace algunos años se ha analizado la idea de crear una corte internacional de derechos humanos, con competencia para conocer sobre casos relativos a violaciones de derechos humanos cometidos por empresas. Sin embargo, ante la aparente polarización previo y durante la primera sesión del Grupo de Trabajo intergubernamental, dicha posibilidad parece de difícil realización. Para una discusión preliminar sobre el tema, véase Nowak, M., "The Need for a World Court of Human Rights", Human Rights Law Review, vol. 7 (1), 2007, pp. 256-257. 
Esta revista forma parte del acervo de la Biblioteca Jurídica Virtual del Instituto de Investigaciones Jurídicas de la UNAM

empresas que operen en su jurisdicción (es decir, de forma territorial) o que estén registradas en su país (lo cual por ende podría implicar también medidas de regulación de carácter extraterritorial). En otras palabras, la probabilidad principal es que el instrumento que se adopte posiblemente continúe operando bajo el modelo de responsabilidad indirecta que ha sido la norma bajo el derecho internacional.

Aún así, existen importantes interrogantes que deberán ser resueltas en el marco de las discusiones del tratado: por ejemplo, ¿cómo podría el sistema de comunicaciones individuales ser reformado para examinar tanto las acciones del Estado como de las empresas involucradas en una presunta violación de derechos humanos? ¿Cómo podría mejorarse el sistema de "reparaciones" que existe en el marco de los órganos de tratado? ¿Tendría el órgano creado competencia para supervisar las acciones tanto de Estados como de empresas, incluso a través de los informes periódicos que se utilizan en el contexto de los comités? Indudablemente, estas y otras preguntas deberán ser resueltas por el Grupo de Trabajo intergubernamental para determinar la forma de crear un órgano que tenga una mayor efectividad que la que se ha conseguido hasta ahora por los otros comités, particularmente en torno a las cuestiones de comunicaciones e informes periódicos. Particularmente en la cuestión de las comunicaciones, una reformulación del procedimiento relativamente estandarizado que se ha adoptado a través de los comités podría ser una opción deseable e interesante, sobre todo si se considera la posibilidad de que las empresas (como responsables directas) y los Estados (como responsables indirectos) puedan comparecer en casos específicos ante el órgano resultante, con la finalidad de dirimir las controversias que tengan lugar a través de la mediación o conciliación, o de no ser posible, que se adopten vistas tendientes a señalar las violaciones cometidas tanto por empresas como por el Estado y, en su caso, que se dicten medidas de reparación a favor de las víctimas. ${ }^{63}$

Como se podrá observar, en el alba del funcionamiento del Grupo de Trabajo intergubernamental sobre un tratado de empresas y derechos humanos sobresalen las dudas respecto a cuestiones tanto sustantivas como procesales. Este tema, que durante tantas décadas ha sido debatido en el

63 Una interesante opción sería seguir el modelo instituido por el Comité de Derechos Humanos; véase al respecto David, V., "Reparations at the Human Rights Committee: Legal Basis, Practice and Challenges”, Netherlands Quarterly of Human Rights, vol. 32 (1), 2014. 
seno de las Naciones Unidas y otras organizaciones internacionales, finalmente tiene una oportunidad clara de concretizar sus objetivos y propuestas en un instrumento vinculante. Debido a su complejidad técnica, se espera que las discusiones se prolonguen durante varios años, en un esfuerzo por consagrar finalmente la obligación empresarial de respetar los derechos humanos y, eventualmente, de colaborar en su protección e implementación a nivel doméstico. Las cuestiones señaladas en los párrafos precedentes son algunas de los diversos aspectos que sin duda habrán de discutirse durante el ciclo del Grupo de Trabajo intergubernamental, y en particular durante las dos primeras sesiones, que servirán para informar la propuesta que deberá ser hecha por el presidente-relator del Grupo previo a la tercera sesión.

\section{BREVES REFLEXIONES SOBRE LA PRIMERA SESIÓN DEL GRUPO DE TRABAJO INTERGUBERNAMENTAL DE COMPOSICIÓN ABIERTA SOBRE EL PROYECTO DEL TRATADO}

La primera sesión del Grupo de Trabajo intergubernamental tuvo lugar entre el 6 y 10 de julio de 2015 en la Sala de los Derechos Humanos y de la Alianza de las Civilizaciones, en Ginebra, con la participación de aproximadamente 50 Estados y numerosas organizaciones no gubernamentales con estatus consultivo ante el ECOSOC. Con algunas semanas de anticipación a la sesión, la Secretaría del Grupo de Trabajo circuló un programa de trabajo, que inicialmente incluiría bajo su cuarto punto de agenda siete paneles temáticos, referentes de forma general a los principios que integrarían un instrumento internacional en la materia, a su alcance y al contenido que debería incluir. Tras una elección unánime de la embajadora de Ecuador como presidenta-relatora del Grupo de Trabajo intergubernamental, que claramente había sido acordada con los demás Estados participantes, se procedió a la adopción de la agenda y programa de trabajo.

En una posición que fue fuertemente criticada tanto por Estados como por representantes de la sociedad civil (y que incluso ha sido considerada como un intento de sabotaje de la sesión), la delegación de la Unión Europea, apoyada por Francia y Luxemburgo, propuso a la recién electa presidenta del Grupo de Trabajo intergubernamental dos modificaciones al 
Esta revista forma parte del acervo de la Biblioteca Jurídica Virtual del Instituto de Investigaciones Jurídicas de la UNAM

programa, condicionando su participación en los trabajos del Grupo a su aceptación: en primer lugar, que se incluyera un panel referente a los Principios Rectores sobre empresas y derechos humanos y su implementación a nivel interno, y en segundo lugar la inclusión de la palabra "todas" antes de "las demás empresas de negocios" en el programa de trabajo para la primera sesión. ${ }^{64}$ Diversas reflexiones deben hacerse sobre esta situación: en primer lugar, el llamado a incluir un panel sobre la implementación de los Principios Rectores obedece a distintos factores. La Unión Europea, tanto a nivel institucional como en sus Estados miembros, ha sido el único bloque regional que ha adoptado estrategias y lineamientos para desarrollar una agenda sobre la promoción e implementación de los Principios Rectores a nivel interno.

De la misma forma, la implementación del marco de la ONU a través de planes nacionales de acción ha ocurrido a la fecha únicamente en países europeos, lo cual podría servir para reflejar tanto que a nivel interno de esos países se han adoptado medidas para asegurar que las empresas respeten los derechos humanos, como que los demás países (incluso aquellos que propusieron la creación del Grupo de Trabajo intergubernamental, Ecuador y Sudáfrica) no han hecho el mínimo esfuerzo posible para adaptar su marco jurídico interno a las recomendaciones estipuladas en los Principios Rectores.

Por otra parte, la inclusión de un panel sobre los Principios Rectores posiblemente fue propuesto para atenuar la percepción de dicotomía que existe entre el proyecto del tratado y la implementación del marco de la ONU, y con ello, para asegurar que los Principios Rectores sean un elemento básico que esté presente en las discusiones del proyecto de tratado. A nivel logístico ese llamado de última hora para alterar el programa de trabajo sufrió de la falta de una preparación adecuada del panel (particularmente en cuanto al número de intervenciones), aunque a la distancia la impresión es que los Principios Rectores, aún si no se hubiera incluido dicho panel, de cualquier manera habrían sido un elemento intrínseco en el desarrollo de la sesión.

En cuanto a la segunda propuesta de la Unión Europea, de incluir la palabra "todas" antes de "las demás empresas de negocios", la cuestión es par-

64 Algunas delegaciones (como Cuba, Sudáfrica, Pakistán o Bolivia, El Salvador, Venezuela, India, Egipto e Indonesia, entre otras) y organizaciones no gubernamentales, sin embargo, interpretaron la propuesta de la Unión Europea como un llamado a modificar el texto de la resolución 26/9 adoptada por el Consejo de Derechos Humanos. 
ticularmente distinta. En los meses previos a la sesión, la posición común de numerosos Estados y organizaciones no gubernamentales había sido de utilizar este Grupo de Trabajo intergubernamental para que el instrumento fuera dirigido únicamente a empresas transnacionales. Sin embargo, la inclusión de la palabra "todas" tendría la intención de asegurar que el instrumento tenga un impacto en todas las empresas, independientemente de si sus operaciones se realizan de forma coordinada a nivel transnacional o si únicamente trabajan en una jurisdicción.

Ello podría generar dos efectos: crear un instrumento cuya implementación en la práctica sea inefectivo, ante la incapacidad de mecanismos internacionales o incluso nacionales de dar un seguimiento preciso a las actividades de millones de empresas, con operaciones transnacionales o no; o bien, desde un punto de vista jurídico, asegurar que el instrumento no exima a las empresas con sede en países en vías de desarrollo de cumplir con las obligaciones que eventualmente llegasen a ser estipuladas en el tratado, y con ello, que se diluyera el excesivo enfoque en las empresas de países desarrollados.

La modificación del texto del programa de trabajo para la primera sesión habría tenido un efecto práctico limitado, puesto que las intervenciones de los expertos invitados seguramente no habrían variado de forma significativa, y las primeras dos sesiones tienen por objetivo la discusión e intercambio de ideas para informar el proyecto de instrumento. Por el contrario, si la propuesta hubiera sido modificar el texto de la resolución 26/9 adoptada por el Consejo de Derechos Humanos (como algunos participantes en la sesión lo interpretaron), ello habría generado por lo menos una cuestión de mayor relevancia, aunque de carácter primordialmente procedimental: al ser el Grupo de Trabajo intergubernamental un órgano creado en virtud de una resolución del Consejo, parece pertinente preguntar cuál sería su competencia para modificar una decisión de un órgano superior. En principio, la lógica sugeriría que toda modificación de un mandato otorgado correspondería únicamente al Consejo de Derechos Humanos, quien en una sesión regular podría sujetar dicha propuesta a votación. En ese sentido, la propuesta de la Unión Europea en principio habría sido factible respecto a la modificación del Programa de Trabajo (al estar dentro de la competencia del Grupo de Trabajo intergubernamental), aunque no en torno a la modificación del contenido de la resolución 26/9. 
Esta revista forma parte del acervo de la Biblioteca Jurídica Virtual del Instituto de Investigaciones Jurídicas de la UNAM

Conforme a las Reglas de Procedimiento de la Asamblea General de las Naciones Unidas, que rigen también las actuaciones del Consejo de Derechos Humanos y de los órganos derivados de éste, la moción de la Unión Europea debería haber sido sujeta a discusiones ${ }^{65}$ (que en la práctica tuvieron lugar) y posteriormente a un voto. Sin embargo, sin haber llamado a un voto, la presidenta-relatora del Grupo de Trabajo intergubernamental determinó adoptar el Programa de Trabajo modificado, incluyendo la primera propuesta de la Unión Europea sobre incluir un panel relativo a la implementación de los Principios Rectores a nivel interno. ${ }^{66}$

A pesar de este accidentado comienzo a la primera sesión, el Programa de Trabajo se desarrolló por lo general conforme a lo previsto. Así, se organizaron ocho paneles temáticos, divididos en cuatro grandes áreas: la implementación de los Principios Rectores sobre las empresas y los derechos humanos, los principios para el proyecto de tratado, el alcance de un futuro instrumento vinculante ${ }^{67}$ y finalmente su posible contenido. ${ }^{68} \mathrm{De}$ forma general, tres grandes temas resaltaron en las discusiones sostenidas entre los expertos, los Estados y las organizaciones de la sociedad civil que participaron en la primera sesión: la profundidad que debe tener el eventual futuro instrumento (dimensión vertical), su amplitud (dimensión horizontal) y las obligaciones de los Estados para asegurar una mejor y más efectiva protección de los derechos humanos. Desde luego, algunas de estas

65 Asamblea General, Reglamento de la Asamblea General, A/520/Rev.17 (abril de 2008), Regla 78.

66 Sobre este punto, la posición de México (con el apoyo de Chile y Uruguay) fue determinante para lograr una solución de compromiso, que permitiera la inclusión del panel propuesto por la Unión Europea, y logrando que se discutiera de forma posterior la modificación - o no- del Programa de Trabajo y de la resolución.

67 Dos paneles se organizaron en torno al alcance: el primero sobre la definición y la naturaleza jurídica conforme al derecho internacional de las empresas transnacionales y otras empresas comerciales, y el segundo respecto a qué derechos humanos deben estar protegidos por el instrumento ante las actividades de las empresas.

68 Bajo este rubro se organizaron cuatro paneles temáticos, respecto a las obligaciones de los Estados de garantizar el respeto de los derechos humanos por las empresas, incluso a través de obligaciones extraterritoriales; sobre las obligaciones de las empresas de prevenir las violaciones de derechos humanos y los estándares para su prevención y reparación; sobre los estándares para la determinación de la responsabilidad jurídica de las empresas y las conductas que la originarían; y finalmente, sobre los mecanismos nacionales e internacionales de reparación, la cooperación judicial internacional, y el Proyecto de Rendición de Cuentas y Mecanismos de Reparación de la Oficina del Alto Comisionado para los Derechos Humanos. 
Esta revista forma parte del acervo de la Biblioteca Jurídica Virtual del Instituto de Investigaciones Jurídicas de la UNAM

cuestiones ya han sido abordadas en la sección anterior, por lo que los breves comentarios que a continuación se expondrán buscan reflejar la manera en que dichos temas fueron considerados por los participantes en la sesión.

Respecto a la profundidad del instrumento que comenzará a ser discutido a partir de 2017 en el marco de la tercera sesión del Grupo de Trabajo intergubernamental, la discusión se ha concentrado en argumentar los motivos para que el instrumento se enfoque, por una parte, en las empresas transnacionales (o como ya se ha mencionado supra, en aquellas que realizan operaciones de carácter transnacional ${ }^{69}$ ), o por la otra - y en concordancia con la propuesta de la Unión Europea-, a todas las empresas, independientemente de su tamaño o giro.

En general, respecto a este tema hubo una tendencia inclinada hacia sujetar a las empresas transnacionales al instrumento internacional, en virtud de su poderío económico, la facilidad para moverse entre jurisdicciones (y con ello escapar a la competencia de los Estados según su conveniencia o necesidad) y para aprovechar las lagunas existentes tanto bajo el derecho internacional como bajo el derecho interno. ${ }^{70} \mathrm{~A}$ pesar de que la posición de la delegación de la Unión Europea podría haber sido factual y jurídicamente correcta al señalar que cualquier empresa puede tener impactos negativos en los derechos humanos, independientemente de su tamaño o la naturaleza de las operaciones, su abandono (así como el de Francia) de la sesión impidió profundizar en los méritos de la propuesta, a pesar de que incluso algunas de las ONG de mayor envergadura y posición en el tema (como la FIDH) compartían de cierto modo dicha perspectiva..$^{71}$ En general, parece que hay una fijación con la figura que representan las empresas con operaciones transnacionales, particularmente respecto de aquellas provenientes de países desarrollados con actividades en África, América Latina o Asia.

69 Open-ended intergovernmental working group on transnational corporations and other business enterprises with respect to human rights, Draft Report of the First Session, A/ HRC/ / (10 July 2015), §55 (en http: / /www.ohchr.org/Documents/HRBodies/HRCouncil/WGTransCorp/Session $1 /$ Draftreport.pdf).

70 Ibidem, §53. Algunas delegaciones reconocieron durante la sesión la inexistencia de la figura jurídica de "empresa transnacional”, por lo que se sugirió concentrar el objetivo del instrumento en las operaciones de carácter transnacional que empresas de distintas nacionalidades realizan de forma coordinada para un objetivo común.

71 Cabe resaltar que algunos países, incluyendo a México, Chile y Uruguay, respaldaron dicha propuesta. 
Esta revista forma parte del acervo de la Biblioteca Jurídica Virtual del Instituto de Investigaciones Jurídicas de la UNAM

Sin embargo, es posible que conforme avancen las negociaciones y sesiones del Grupo de Trabajo intergubernamental, la posición común de los distintos países vaya refinándose para concentrarse, como fue señalado en los debates durante las sesiones, en las lagunas provocadas directamente por las operaciones transnacionales de las empresas.

En lo que respecta a la dimensión horizontal, es decir a la amplitud que debería tener el instrumento, la discusión (previa y durante la sesión) se concentró en la necesidad de que el instrumento sea amplio y que cubra la protección de todos los derechos humanos, o bien, que sea un instrumento de carácter minimalista (es decir, concentrado únicamente en las más graves violaciones a los derechos humanos que pudieran a su vez constituir crímenes internacionales). La ausencia de la mayor parte de los países integrantes del bloque occidental, que son los que en un principio podrían haber apoyado esta propuesta, generó que la discusión fuera sólo por referencia a posiciones expresadas previamente, sin que verdaderamente existiera un debate en la Sala XX. Tomando en cuenta el respaldo unánime a los Principios Rectores, el único motivo por el que se buscaría adoptar un instrumento internacional con un alcance reducido sería con la finalidad de lograr una aceptación relativamente indiscutida y rápida del mismo. No obstante, la posición general en el seno del Grupo de Trabajo intergubernamental fue en torno a la adopción de un instrumento internacional que proteja por igual todos los derechos humanos, respetando sus principios de indivisibilidad, interrelación e interdependencia. ${ }^{72}$

Finalmente, una tercera cuestión que sobresalió entre los debates fue relativa a las obligaciones de los Estados de proteger los derechos humanos frente a las actividades de las empresas. Numerosas referencias a los pilares I y III de los Principios Rectores de la ONU sobre las empresas y los derechos humanos fueron hechas por las delegaciones de los Estados y las organizaciones de la sociedad civil, así como por los expertos invitados a la sesión, particularmente en torno a la necesidad de mejorar la cooperación internacional entre Estados en casos que involucren violaciones a los derechos humanos cometidos por empresas (o con su participación

72 Lo anterior fue reflejado en el proyecto de informe presentado por la secretaría del Grupo de Trabajo de composición abierta: Open-ended intergovernmental working group on transnational corporations and other business enterprises with respect to human rights, Draft Report of the First Session, A/HRC// (10 de Julio de 2015), §56 (en http://www.ohchr. org/Documents /HRBodies/HRCouncil/WGTransCorp/Session1 / Draftreport.pdf). 
Esta revista forma parte del acervo de la Biblioteca Jurídica Virtual del Instituto de Investigaciones Jurídicas de la UNAM

o colaboración), a la adopción de medidas regulatorias y jurisdiccionales con efecto o alcance extraterritorial, y a la estandarización de sus marcos normativos para incluir plenas obligaciones de las empresas de respetar los derechos humanos.

La principal atención se centró en dos cuestiones: el problema de la extraterritorialidad, por una parte, y de la jerarquía de los derechos humanos ante los instrumentos internacionales de protección de inversiones. Como ya se ha señalado, algunos puntos sustantivos de ambos temas han sido discutidos con antelación, ${ }^{73}$ por lo que únicamente cabría añadir que hubo de manera general un amplio consenso entre los participantes respecto a la necesidad de colmar las lagunas jurídicas existentes en torno a la cuestión de la jurisdicción y regulación extraterritoriales, por una parte, y de determinar la existencia de una jerarquía normativa bajo el derecho internacional. Claramente, ante la ausencia de los principales países desarrollados en la sesión, no existió una verdadera contraposición y debate respecto a la factibilidad y retos jurídicos que existirían en ambos temas, que sin duda continuarán en la agenda de las sesiones venideras del Grupo de Trabajo intergubernamental.

\section{CONCLUSIONES}

De forma general, se puede concluir que la primera sesión del Grupo de Trabajo intergubernamental — a pesar de la retirada de los países europeos y de la inasistencia de Estados como Japón, Noruega, Canadá, Reino Unido o los Estados Unidos de América - tuvo unas buenas discusiones

73 Tanto en el cuerpo de este texto como en otras publicaciones. Sobre la cuestión de la extraterritorialidad, véanse Cantú Rivera, H., "Developments in Extraterritoriality and Soft Law: Towards New Measures to Hold Corporations Accountable for their Human Rights Performance?", Anuario Mexicano de Derecho Internacional, vol. XIV, 2014, pp. 731-749; Bernaz, N., op. cit.; Deva, S., "Corporate Human Rights Violations: A Case for Extraterritorial Regulation” en Luetge, Ch. (ed.), Handbook of the Philosophical Foundations of Business Ethics, Heidelberg, Springer, 2012, pp. 1080-1086; Knox, J. H., "A Presumption Against Extrajurisdictionality”, American Journal of International Law, vol. 104, 2010. 
Esta revista forma parte del acervo de la Biblioteca Jurídica Virtual del Instituto de Investigaciones Jurídicas de la UNAM

iniciales sobre la adopción de un instrumento internacional vinculante, ${ }^{74} \mathrm{en}$ particular por su apertura hacia las organizaciones de la sociedad civil. Sin embargo, sería deseable que en aras de contar con un debate constructivo y comprometido con mejorar la protección de los derechos humanos afectados por las actividades de las empresas, se pudieran lograr los consensos necesarios para involucrar por lo menos a las delegaciones europeas, que de forma general han liderado el tema de las empresas y los derechos humanos en el marco de los Principios Rectores. En ese mismo sentido, sería conveniente que en el marco de las organizaciones regionales existentes ${ }^{75}$ se continúe la discusión sobre el tema, no sólo respecto a la adopción de instrumentos o declaraciones regionales en la materia, sino también sobre la manera de ligar los procedimientos que puedan existir de forma paralela entre organizaciones regionales y las Naciones Unidas. Sólo con esfuerzos coordinados a nivel nacional, regional y universal, y con una amplia participación de los diferentes actores involucrados podrá este tema finalmente pasar de las discusiones a su instrumentalización, y con ello a la protección de las víctimas de violaciones de los derechos humanos en la práctica.

\section{BIBLIOGRAFÍA}

ADDO, M. K., "El mandato del Grupo de Trabajo sobre empresas y derechos humanos: Ideas preliminares", en MARTínEZ GARZA, M. E. y CANtú Rivera, H. F. (comp.), El futuro es hoy: Construyendo una agenda de derechos humanos, Monterrey, CEDHNL-UANL, 2013.

"A gora: Reflections on Kiobel”, American Journal of International Law, vol. 107, 2013.

BAIR, J., "Corporations at the United Nations: Echoes of the New International Economic Order?”, Humanity: An International Journal of Human Rights, Humanitarianism, and Development, vol. 6 (1), 2015.

74 En ese sentido, véase López, C., "International Talks on a Treaty on Business \& Human Rights: A Good Start to a Bumpy Road”, 2015, en http://business-humanrights.org/en/international-talks-on-a-treaty-on-business-human-rights-a-good-start-to-a-bumpy-road.

75 La Organización de Estados Americanos, la Unión Europea, la Unión Africana o la Asociación de Naciones del Sudeste Asiático (ASEAN en inglés). 
Esta revista forma parte del acervo de la Biblioteca Jurídica Virtual del Instituto de Investigaciones Jurídicas de la UNAM

Bilchitz, D., "A chasm between 'is and 'ought'? A critique of the normative foundations of the SRSG's Framework and the Guiding Principles", en Deva, S. y Bilchitz, D. (eds.), Human Rights Obligations of Business: Beyond the Corporate Responsibility to Respect?, Cambridge, Cambridge University Press, 2013.

BUCHER, A., 'La compétence universelle civile', Recueil des cours, vol. 372, 2015.

CANTú Rivera, H. F., "Empresas y derechos humanos: ¿hacia una regulación jurídica efectiva o el mantenimiento del status quo?”, Anuario Mexicano de Derecho Internacional, vol. XIII, 2013.

-, "Regional Approaches in the Business \& Human Rights Field", L'Observateur des Nations Unies, vol. 35, 2013.

-, "The Kiobel Precedent and its Effects on Universal Jurisdiction and the Business \& Human Rights Agenda”, Cuestiones Constitucionales, núm. 30, 2014.

, "Developments in Extraterritoriality and Soft Law: Towards New Measures to Hold Corporations Accountable for their Human Rights Performance?", Anuario Mexicano de Derecho Internacional, vol. XIV, 2014. , "Towards Judicial Accountability in the Business \& Human Rights Field?", en Moura Vicente, D. (ed.), Towards a Universal Justice? Putting International Courts and Jurisdictions into Perspective, Leiden, Brill, 2015.

-, "The United Nations Guiding Principles on Business and Human Rights in the European Union: From Regional Action to National Implementation”, en Martin, J. y Bravo, K. E. (eds.), The Business and Human Rights Landscape: Moving Forward, Looking Back, Cambridge, Cambridge University Press, 2015.

, "La OCDE y los derechos humanos: el caso de las Directrices para Empresas Multinacionales y los Puntos de Contacto Nacional”, Anuario Mexicano de Derecho Internacional, vol. XV, 2015.

ČERnIČ, J. L. yVAN Ho, T. (eds.), Human Rights and Business: Direct Corporate Accountability for Human Rights, Nijmegen, Wolf Legal Publishers, 2015. Clapham, A., Human Rights Obligations of Non-State Actors, Oxford, Oxford University Press, 2006.

DARCY, S., “A New Business and Human Rights Instrument?", p. 2, artículo presentado durante la sesión de lluvia de ideas sobre empresas y derechos humanos titulada "Access to Justice and Extraterritorial Obligations”, del 26 de febrero de 2015 en Ginebra, en http://www. 
Esta revista forma parte del acervo de la Biblioteca Jurídica Virtual del Instituto de Investigaciones Jurídicas de la UNAM

fes-globalization.org/geneva / documents /2015/2015_2_26_Darcy_Contri bution\%20to\%20Roundtable\%20-\%20Geneva.pdf.

DAVID, V., "Reparations at the Human Rights Committee: Legal Basis, Practice and Challenges", Netherlands Quarterly of Human Rights, vol. 32 (1), 2014.

Deva, S., Regulating Corporate Human Rights Violations: Humanizing Business, Londres, Routledge, 2012.

, "Corporate Human Rights Violations: A Case for Extraterritorial Regulation”, en LUETGE, Ch. (ed.), Handbook of the Philosophical Foundations of Business Ethics, Heidelberg, Springer, 2012.

, "Treating Human Rights Lightly: a Critique of the Consensus Rhetoric and the Language Employed by the Guiding Principles", en Deva, S. y Bilchitz, D. (eds.), Human Rights Obligations of Business: Beyond the Corporate Responsibility to Respect?, Cambridge, Cambridge University Press, 2013.

DupuY, P. M. et al. (eds.), Human Rights in International Investment Law and Arbitration, Oxford, Oxford University Press, 2009.

Felice, D. de y Graf, A., "The Potential of National Action Plans to Implement Human Rights Norms: An Early Assessment with Respect to the UN Guiding Principles on Business and Human Rights", Journal of Human Rights Practice, vol. 7 (1), 2015.

Frouville, O. de, "Attribution of Conduct to the State: Private Individuals”, en CRAWFORD, J. et al. (eds.), The Law of International Responsibility, Oxford, Oxford University Press, 2010.

HirsCH, M., "Interactions Between Investment and Non-investment Obligations”, en MuCHLINSKI, P. et al. (ed.), The Oxford Handbook of International Investment Law, Oxford, Oxford University Press, 2008.

InAZumi, M., Universal Jurisdiction in Modern International Law: Expansion of National Jurisdiction for Prosecuting Serious Crimes under International Law, Cambridge, Intersentia, 2005.

JäGERS, N., Corporate Human Rights Obligations: In Search of Accountability, Antwerp, Intersentia, 2002.

-, "UN Guiding Principles on Business and Human Rights: Making Headway Towards Real Corporate Accountability?", Netherlands Quarterly of Human Rights, vol. 29 (2), 2011.

Karamanian, S. L., "The Place of Human Rights in Investor-State Arbitration”, Lewis \& Clark Law Review, vol. 17 (2), 2013. 
Esta revista forma parte del acervo de la Biblioteca Jurídica Virtual del Instituto de Investigaciones Jurídicas de la UNAM

KnOX, J. H., "A Presumption Against Extrajurisdictionality”, American Journal of International Law, vol. 104, 2010.

LATTY, F., "Actions and Omissions”, en CrawfOrd, J. et al. (eds.), The Law of International Responsibility, Oxford, Oxford University Press, 2010.

LENHOFF, A., "International Law and Rules on International Jurisdiction", Cornell Law Review, vol. 50, 1964.

LÓPEZ, C. "International Talks on a Treaty on Business \& Human Rights: A Good Start to a Bumpy Road”, 2015, en http: / /business-humanrights.org/ en/international-talks-on-a-treaty-on-business-human-rights-a-good-start-toa-bumpy-road.

McCorquodale, R., "Waving Not Drowning: Kiobel Outside the United States", American Journal of International Law, vol. 107, 2013.

Meshel, T., "Human Rights in Investor-State Arbitration: The Human Right to Water and Beyond", Journal of International Dispute Settlement, vol. 6 (2), 2015.

MorgerA, E., Corporate Accountability in International Environmental Law, Nueva York, Oxford University Press, 2009.

Nowak, M., "The Need for a World Court of Human Rights", Human Rights Law Review, vol. 7 (1), 2007.

Pérez Correa Camarena, F., "El Alien Tort Statute: el imperialismo judicial de los valores occidentales", Revista de la Facultad de Derecho de México, núm. 260, 2013.

PITTS, Ch., "For a Treaty on Business \& Human Rights", artículo presentado en el seminario Does the World Need a Treaty on Business and Human Rights? Weighing the Pros and Cons.

REDFIELD, S., "Searching for Justice: The Use of Forum Necessitatis", Georgetown Journal of International Law, vol. 45.

Ruggie, J. G., Just Business: Multinational Corporations and Human Rights, Nueva York, W. W. Norton \& Co., 2013.

-, "A UN Business and Human Rights Treaty? An Issues Brief" (28 de enero de 2014), p. 5, en http://business-humanrights.org/sites/default/fi les /media /documents/ruggie-on-un-business-human-rights-treaty-jan-2014. $p d f$.

Ruggie, J., Quo Vadis? Unsolicited Advice to Business and Human Rights Treaty Sponsors (9 de septiembre de 2014), disponible en: http://www.ihrb.org/ commentary / quo-vadis-unsolicited-advice-business. html. 
Esta revista forma parte del acervo de la Biblioteca Jurídica Virtual del Instituto de Investigaciones Jurídicas de la UNAM www.juridicas.unam. $\mathrm{mx}$

Sauvant, K. P., "The Negotiations of the United Nations Code of Conduct on Transnational Corporations: Experience and Lessons Learned", The Journal of World Investment \&Trade, vol. 16, 2015.

SCHutTer, O. de, "Les affaires Total et Unocal: Complicité et extraterritorialité dans l'imposition aux entreprises d'obligations en matière de droits de l'homme", Annuaire français de droit international, 2006.

- Extraterritorial Jurisdiction as a Tool for Improving the Human Rights Accountability of Transnational Corporations (22 de diciembre de 2006). -, "La responsabilité des États dans le contrôle des sociétés transnationales: vers une convention internationale sur la lutte contre les atteintes aux droits de l'homme commises par les sociétés transnationales”, en DECAUX, E. (ed.), La responsabilité des entreprises multinationales en matière de droits de l'homme, Bruselas, Bruylant, 2010.

Shelton, D., "Normative Hierarchy in International Law", American Journal of International Law, vol. 100, 2006.

SimmA, B., "Foreign Investment Arbitration: A Place for Human Rights?", International and Comparative Law Quarterly, vol. 60, 2011.

SuDA, R., "The Effect of Bilateral Investment Treaties in Human Rights Enforcement and Realization”, en DE SCHUTTER, O. (ed.), Transnational Corporations and Human Rights, Oxford, Hart, 2006.

WeT, E. de y Vidmar, J., "Conflicts Between International Paradigms: Hierarchy versus Systemic Integration”, Global Constitutionalism, vol. 2 (2), 2013. 